\title{
A Bayesian stochastic frontier: an application to agricultural productivity growth in European countries
}

\section{A. Tonini}

Received: 1 December 2010/Accepted: 14 September 2011/Published online: 30 September 2011

(C) The Author(s) 2011. This article is published with open access at Springerlink.com

\begin{abstract}
This paper measures and compares total factor productivity (TFP) growth in agriculture for the European Union (EU) countries and candidate countries (CC), in order to distinguish and investigate cross-country differences in agricultural productivity growth rates from 1993 to 2006. A stochastic production frontier model is estimated using a Bayesian approach capturing country-specific time-invariant heterogeneity and country-specific time-varying inefficiency. Agricultural productivity growth is found to be mostly driven by technological change. The TFP growth rates of the EU-12 countries and CC are about twice the EU-15 growth rate. Catch-up in productivity levels is observed between EU-15 and EU-12 as well as between EU-15 and CC. The results are compared for a situation in which country-specific time-invariant heterogeneity is not taken into account.
\end{abstract}

Keywords Bayesian inference $\cdot$ Stochastic production frontier - Time-varying technical inefficiency - Total factor productivity growth · European agriculture

\section{JEL Classification $\quad$ C15 $\cdot$ D24 $\cdot$ O47}

\section{Introduction}

The empirical literature on cross-country (economic) growth can be classified along two main lines (Koop et al. 1999:457). The first, so-called growth accounting, usually specifies a Cobb-Douglas production function where real gross domestic

\footnotetext{
A. Tonini $(\square)$

International Policy Research Area-Agricultural Policy Section, LEI, part of Wageningen UR, P.O. Box 29703, 2502 LS The Hague, The Netherlands

e-mail: axel.tonini@wur.nl; axeltonini@gmail.com
}

A. Tonini

Alexanderveld 5, 2585 DB The Hague, The Netherlands 
product (GDP) linearly depends on capital and labour. Total factor productivity (TFP) is calculated as the residual from the specified production function. In order to explain growth, a two-stage method is used. It entails first calculating TFP and then regressing it on several explanatory variables. Production function parameters are calculated through factor shares without econometrics; in so doing, every country is characterized by its own production technology. The second line, so-called cross-country growth regression, also starts from a Cobb-Douglas specification but relies on econometric techniques. Parameter homogeneity is usually assumed, implying that all countries are characterized by a similar production technology with disembodied technological change.

This paper attempts to estimate and compare TFP growth in agriculture for the European Union (EU) countries and for candidate countries (CC). The objective is to estimate and investigate cross-country differences in agricultural productivity growth rates. These differences should explain any discrepancy between agricultural productivity in the new member states (EU-12) and CC and agricultural productivity in the former EU-15 countries. The paper addresses the following main questions: Is agricultural productivity growth driven by increases in efficiency bringing countries closer to the frontier? Or is it driven by movements of the frontier or along the frontier itself? Is there any evidence of country catch-up?

The data used are drawn from the FAOSTAT (2010) database of the Statistics Division of the Food and Agriculture Organization (FAO). This database, which has been used in similar analyses (Coelli and Prasada Rao 2005; Fulginiti and Perrin 1997; Suhariyanto and Thirtle 2001), comprises data on the former EU-15 countries, the EU-12 and three CC (Croatia, the Former Yugoslav Republic of Macedonia, and Turkey). The data used are for the period from 1993 to 2006, in order to allow for the inclusion of new independent states.

A parametric stochastic frontier approach is used in this paper for three reasons. First, the formal treatment of technical efficiency ${ }^{1}$ in stochastic frontier models allows the issue of output growth to be disentangled to provide an interpretation of the unexplained residual that in the growth accounting is labelled as technical change. Second, the approach explicitly takes into account measurement error and the potential effect of unfavourable weather and disease-factors that frequently affect agriculture. Finally, the approach used here deviates from the classical crosscountry growth regression literature, since the interest is in estimating productivity growth rather than explaining it. The focus is therefore on analyzing the properties of the distribution of agricultural output that is conditional on key agricultural inputs, and is empirically based on production theory. For a comprehensive overview on frontier techniques, see Murillo-Zamorano (2004).

The standard assumption of a common production technology is initially relaxed by estimating a model capturing country-specific time-invariant heterogeneity. This

\footnotetext{
1 Technical efficiency is a particularly useful and neutral concept for assessing the performance of former socialist countries, because it focuses solely on the maximum attainable output level for a given set of inputs. As Brada et al. (1997:107) argues technical efficiency is a necessary, though not in itself sufficient, condition for profit maximization; it is also a precondition for fulfilling output plans, as they existed in former collective and state-owned farms.
} 
is done by extending the 'true' fixed effects (TFEs) stochastic frontier model developed by Greene $(2004,2005)$. Latent class models have also been used to identify different technologies for analyzing different classes (Alvarez and Corral 2010). The reason it is important to capture potential country-specific time-invariant heterogeneity is that countries vary in their stage of development, and physical factors such as soil quality, drainage, relief and climate. Kumbhakar and Hjalmarsson (1993) highlighted that in the past literature inefficiency estimates were contaminated by producer heterogeneity unrelated to efficiency.

A Bayesian estimation is used because it allows us to: (1) derive precise smallsample results, which is especially relevant when the data set is $\operatorname{small}^{2}$; (2) derive the full posterior distribution of any individual efficiency; (3) consider parameter uncertainty by providing a probability distribution for each estimated parameter; (4) impose regularity conditions on the parameters that will be estimated consistently through the specification of the prior. For a more in-depth discussion on the advantages of using Bayesian estimation in a stochastic frontier framework, see Koop et al. (1999).

In order to estimate the changes in technical efficiency, the time-varying inefficiency model of Cuesta (2000) is introduced in a Bayesian framework, thereby allowing country-specific temporal variation in technical efficiency to be captured. This relaxes the standard assumption of imposing a common temporal pattern of technical inefficiencies on all countries as in Battese and Coelli (1992). Using an approach similar to that described in Terrell (1996), theoretical restrictions are enforced during the estimation in order to fulfil the economic requirements of a well-behaved production frontier). By so doing, technical efficiency scores complying with microeconomic theory ${ }^{3}$ can be derived.

The paper is structured as follows. Section 2 contains the model of TFP growth. Section 3 describes the Bayesian stochastic frontier estimation. Section 4 introduces the data used. Section 5 provides and discusses the results. Finally, Section 6 concludes.

\section{Modelling TFP growth}

In this paper, a stochastic production frontier is estimated in order to measure TFP. A TFP index measures the change in total output relative to changes in the use of all inputs. As such, it is usually preferred above simpler partial productivity measures, which may yield inappropriate results, particularly when countries experience asymmetric changes in inputs (Liefert and Swinnen 2002:23-24). TFP is measured using the so-called Malmquist index (MI) (Caves et al. 1982:1394). The MI has several advantages over the widely used Tornqvist/Fischer index, as discussed in Coelli et al. (1998:246). It can be defined by using either an input or an output

\footnotetext{
${ }^{2}$ In Bayesian econometrics there is no need to draw upon the concept of the performance of the estimator in hypothetical repeated samples (Kennedy 2003).

${ }^{3}$ Estimating efficiency scores without enforcing the required theoretical restrictions may yield spurious estimates. By definition, the region of negative marginal products represents an inefficient stage of production because the extra unit of input leads to a decline in output.
} 
orientation. The proper choice for country-level analysis is an output orientation (Coelli et al. 1998). An output orientation looks for the maximal proportional expansion of an output vector, given an input or resource vector. ${ }^{4}$ The MI used in this study is based on a single output production technology that is equivalent to an output distance function with a single output from which a MI can be defined (Fare and Primont 1995:7-40).

Approaches using stochastic-frontier production functions have been independently proposed by Aigner et al. (1977), Battese and Corra (1977), and Meeusen and van den Broeck (1977). Schmidt and Sickles (1984) extended the production frontier model to panel data. The agricultural production of country $i(i=1, \ldots, N)$ at time $t(t=1, \ldots, T), Y_{i t}$, is assumed to be produced using the input array, $\mathbf{X}_{i t}$ constituted by land $\left(X_{1 i t}\right)$, machinery $\left(X_{2 i t}\right)$, labour $\left(X_{3 i t}\right)$, fertilizer $\left(X_{4 i t}\right)$ and livestock $\left(X_{5 i t}\right)$.

A transcendental logarithmic (i.e. translog) production frontier is selected for its flexibility in measuring TFP growth. The translog functional form is the most frequently used flexible functional form in stochastic frontier analysis. It provides a second-order differential approximation that is linear in parameters. Although, a Cobb-Douglas functional form is parsimonious in terms of parameters to be estimated, a translog production frontier is preferable because it allows production elasticities to vary at each data point and non-neutral Hicksian technological change. The empirical model is specified following the TFEs model of Greene (2004, 2005). A fixed effects model is more adequate than a random effects model, given that our units are countries that can be seen as 'one of a kind' and not extracted as a random draw from some underlying population (Verbeek 2004). The empirical model is specified as follows:

$$
y_{i t}=\alpha_{i}+\sum_{n=1}^{N} \beta_{n} x_{i t n}+\beta_{t} t+\frac{1}{2} \sum_{n=1}^{N} \sum_{m=1}^{N} \beta_{n m} x_{i t n} x_{i t m}+\frac{1}{2} \beta_{t t} t^{2}+\sum_{n=1}^{N} \beta_{n t} x_{i t n} t-z_{i}+\varepsilon_{i t}
$$

where lower case letter $(y, x)$ indicate natural logs of upper case letters $(Y, X), \alpha_{i}$ are country-specific effects capturing time-invariant heterogeneity, $\boldsymbol{\beta}=\left(\beta_{0}, \beta_{1}, \ldots, \beta_{k}\right)$ are the unknown parameters to be estimated, $t$ is a time trend in order to account for technological change. ${ }^{5}$ The inefficiency $z_{i}=-\ln \left(\tau_{i}\right)$ is assigned a non-negative random variable and the random error $\varepsilon_{i t}=\ln \left(\xi_{i t}\right)$ has a symmetric distribution, with mean zero. The results of the TFEs $\operatorname{model}^{6}$ are then compared to the standard (ST) model where time-invariant country-specific heterogeneity is not accounted for $\left(\alpha_{i}=\beta\right)$. Regularity conditions are a priori imposed during the estimation, to ensure that input elasticities are nonnegative at all observed output levels (Terrell 1996) through the following inequality restrictions:

\footnotetext{
${ }^{4}$ Neither an output nor an input orientation affects estimates when constant return to scale is imposed.

5 Technological change in the current translog stochastic frontier specification is specified in order to allow technological change to increase or decrease over time through parameter $\beta_{t t}$ and to account for changes in the marginal rates of technological substitution through the parameters $\beta_{n t}$.

6 The question of whether the TFEs model captures time-invariant heterogeneity or time-invariant inefficiency heterogeneity remains unresolved (Carroll et al. 2011).
} 


$$
E_{x_{i t, n}} \equiv \frac{\partial y_{i t}}{\partial x_{i t n}}=\zeta_{i t, n} \geq 0, \quad \text { for } \quad n=1, \ldots, 5 .
$$

Several time-varying inefficiency models have been suggested in the literature; for a recent overview, see Greene (2009). Two specifications that have proved useful in applications are Kumbhakar's (1990) model,

$$
z_{i t}=z_{i} /\left[1+\exp \left(\gamma_{1} t+\gamma_{2} t^{2}\right)\right]
$$

and Battese and Coelli's (1992) specification,

$$
z_{i t}=z_{i} \exp [\eta(t-T)]
$$

where $\gamma_{1}, \gamma_{2}$ and $\eta$ are parameters to be estimated. The Kumbhakar's (1990) functional form lies in the unit interval and can be non-increasing, non-decreasing, concave or convex. The Battese and Coelli's (1992) function is less flexible but parsimonious in terms of parameters to be estimated. It can be non-increasing or non-decreasing but it is always convex. A drawback of both specifications is that they do not allow for a change in the rank ordering of the unit under analysis over time because the change in technical efficiency is constant and equal across all units. Both specifications can be estimated, assuming that $z_{i}$ has a truncated normal distribution. In this paper, a generalization of Battese and Coelli's (1992) function proposed by Cuesta (2000) is implemented in a Bayesian framework accounting for time-invariant heterogeneity. The Cuesta's (2000) function is specified as

$$
z_{i t}=z_{i} \times \exp \left[\eta_{i}(t-T)\right]
$$

where the temporal pattern of inefficiency effects (i.e. $\eta_{i}$ ) is now a country-specific parameter responsive to different temporal variations among countries. ${ }^{7}$ The technical efficiency of each country in each year is obtained through the conditional expectation of $\exp \left(-z_{i t}\right)$ given the value of $\varepsilon_{i t}-z_{i}$.

In order to measure the MI of TFP growth, the efficiency, technological change and scale components need to be calculated. The efficiency change component is given by:

$$
E C_{i s}=\exp \left(z_{i t}-z_{i s}\right)=z_{i s} / z_{i t}
$$

The technological change component requires the partial derivatives of the production frontier to be evaluated with respect to time, using the data on the $i$-th country in period's $s$ and $t$. Then the technological change between the adjacent period's $s$ and $t$ can be derived through the geometric mean of the aforementioned partial derivatives. In the case of a translog specification, this is equivalent to the exponential of the arithmetic mean of the log derivatives as given by:

$$
T C_{i s}=\exp \left\{\frac{1}{2}\left[\frac{\partial y_{i s}}{\partial s}+\frac{\partial y_{i t}}{\partial t}\right]\right\}
$$

\footnotetext{
7 This specification, as in other models, assumes that inputs are independent of technical inefficiency. Therefore, if they are correlated, the parameter estimates could be biased.
} 
To detect potential scale-change effects, scale change is introduced in computing TFP following Orea (2002), who uses Diewert's quadratic identity to derive an MI. The scale change component is given by:

$$
S C_{i s}=\exp \left\{\frac{1}{2} \sum_{n=1}^{N}\left[\zeta_{i s n} S F_{i s}+\zeta_{i t n} S F_{i t n}\right]\left(x_{i s n} / x_{i t n}\right)\right\}
$$

where $S F_{i s}=\left(\zeta_{i s}-1\right) / \zeta_{i s}, \quad \zeta_{i s}=\sum_{n=1}^{N} \zeta_{i s n}$ (return to scale) and $\zeta_{i s n}=\frac{\partial y_{i s}}{\partial x_{i s n}}$ (input elasticities). Each single component is then summed, to recover the MI of TFP growth.

\section{The Bayesian stochastic frontier model}

This section describes the Bayesian stochastic frontier estimation used. Van den Broeck et al. (1994) introduced Bayesian stochastic frontier models. Bayesian methods appear to be suitable for stochastic frontier models because they provide precise small-sample inference on efficiencies, and they allow prior knowledge and regularities conditions to be incorporated during the estimation and more accurately represent parameter uncertainties through kernel densities. Stochastic frontier models require numeric integration methods because they are so complex; the most appropriate method is the Markov chain Monte Carlo (MCMC) introduced by Koop et al. (1995). In this paper, a MCMC Gibbs sampler following Griffin and Steel (2007) is used. The form of the likelihood function assumes that the inefficiency components $z$ and $\varepsilon$ are independent and that $z$ is a vector of unknown parameters. For simplicity, (1) is rewritten without the $t$ subscript as

$$
y_{i}=\alpha_{i}+\sum_{n=1}^{N} \beta_{n} x_{i n}+\beta_{t} t+\frac{1}{2} \sum_{n=1}^{N} \sum_{m=1}^{N} \beta_{n m} x_{i n} x_{i m}+\frac{1}{2} \beta_{t t} t^{2}+\sum_{n=1}^{N} \beta_{n t} x_{i n} t-z_{i}+\varepsilon_{i} .
$$

The standard corresponding likelihood function is

$$
p\left(y \mid \alpha, \beta, \sigma_{v}^{-2}, z\right)=\prod_{i=1}^{N} \frac{\left(\sigma_{v}^{-2}\right)^{\frac{T}{2}}}{(2 \pi)^{\frac{T}{2}}}\left\{\exp \left[-\frac{1}{2} \sigma_{v}^{-2}\left(\varepsilon_{i}\right)^{\prime}\left(\varepsilon_{i}\right)\right]\right\}
$$

where $\varepsilon_{i}=y_{i}-\alpha_{i}+\sum_{n=1}^{N} \beta_{n} x_{i n}+\beta_{t} t+\frac{1}{2} \sum_{n=1}^{N} \sum_{m=1}^{N} \beta_{n m} x_{i n} x_{i m}+\frac{1}{2} \beta_{t t} t^{2}+\sum_{n=1}^{N} \beta_{n t} x_{i n} t-z_{i}$.

The dependent variable is assumed to follow a normal distribution

$$
y_{i} \sim N\left(\alpha_{i}+\sum_{n=1}^{N} \beta_{n} x_{i n}+\beta_{t} t+\frac{1}{2} \sum_{n=1}^{N} \sum_{m=1}^{N} \beta_{n m} x_{i n} x_{i m}+\frac{1}{2} \beta_{t t} t^{2}+\sum_{n=1}^{N} \beta_{n t} x_{i n} t-z_{i}, \sigma^{2}\right)
$$

where $N\left(\mu, \sigma^{2}\right)$ represents a normal distribution with mean $\mu$ and variance $\sigma^{2}$. Priors are generally specified following Griffin and Steel (2007). The inefficiencies, $z_{i}$, capturing the difference between best practice and actual output, are assumed to have a truncated normal distribution as given by 


$$
z_{i} \sim N^{+}\left(\varsigma, \lambda^{-1}\right)
$$

where $\lambda$ has a gamma distribution

$$
\lambda \sim G a\left(\phi, \lambda_{0}\right)
$$

with $\lambda_{0}=\phi\left(\log \left(r^{*}\right)\right)^{2}$ where $r^{*}$ reflects the prior median efficiency. ${ }^{8}$ The temporal pattern of inefficiency effects [see (5)], $\eta_{i}$, follows a zero mean normal distribution $(\underline{\eta}=0)$ with variance $\underline{\Gamma}=0.25$ characterizing the prior indifference between increasing and decreasing the country-specific temporal pattern of inefficiency effects

$$
\eta_{i} \sim N(\underline{\eta}, \underline{\Gamma}) .
$$

The production frontier parameters $\alpha$ and $\beta$ follow a multivariate normal distribution

$$
\begin{gathered}
\alpha \sim N(\underline{\alpha}, \underline{\Theta}), \\
\beta \sim N\left(\underline{\beta}, \underline{\sum}\right) .
\end{gathered}
$$

with prior mean $\underline{\alpha}=0$ and $\underline{\beta}=0$ and variance $\underline{\Theta}=1.0^{-6}$ and $\underline{\Sigma}=1.0^{-6}$.

The white noise precision, $\left(\sigma_{v}^{-2}\right)$, follows a gamma distribution as given by

$$
\sigma_{v}^{-2} \sim G a\left(\underline{a_{0}}, \underline{a_{1}}\right) .
$$

where the priors are set to $1.0^{-2}$.

Regularity conditions are imposed on the value of the elasticity for the observed output. A non-standard likelihood function is used, in which each observation contributes a likelihood term (Spiegelhalter et al. 2003). The likelihood function is modified, assuming that the data is a set of ones originating from a Bernoulli distribution

$$
p\left(y \mid \alpha, \beta, \sigma_{v}^{-2}, z\right)=\prod_{i=1}^{N} \Psi_{i} \frac{\left(\sigma_{v}^{-2}\right)^{\frac{T}{2}}}{(2 \pi)^{\frac{T}{2}}}\left\{\exp \left[-\frac{1}{2} \sigma_{v}^{-2}\left(\varepsilon_{i}\right)^{\prime}\left(\varepsilon_{i}\right)\right]\right\}=\frac{\Omega_{i}}{C}
$$

where $\Psi_{i}$ is a variable equal to zero for all cases when the regularity conditions in (3) are violated and is equal to one when the regularity conditions are fulfilled, $\Omega_{i}$ are the probabilities of the Bernoulli trials proportional to the likelihood values for which the regularity conditions are satisfied or violated, and $C$ is a constant that ensures that $\Omega_{i}<1$. The conditional distributions of the stochastic frontier model can be found in Koop (2003).

\footnotetext{
${ }^{8}$ In this paper we follow Griffin and Steel (2007) by specifying the shape parameter $\phi=5$ and the scale parameter $r^{*}=0.8$. Appropriate prior values for the shape parameter $\phi$ and scale parameter $r^{*}$ are documented in the literature (see for example Tsionas 2000; Griffin and Steel 2004).
} 


\section{The data}

The data are drawn from the FAOSTAT database ${ }^{9}$ of the Statistics Division of FAO of the United Nations in Rome. The data include the former EU-15 countries as well as the new member states EU-12, notably: Austria, Belgium-Luxembourg, Denmark, Finland, France, Germany, Greece, Ireland, Italy, Netherlands, Portugal, Spain, Sweden, and United Kingdom, Bulgaria, Czech Republic, Cyprus, Estonia, Hungary, Latvia, Lithuania, Malta, Poland, Romania, Slovakia, and Slovenia. In addition, three CC for EU accession are considered: Croatia, Former Yugoslav Republic of Macedonia (FYROM), and Turkey. The data consider the period 1993-2006. The sample comprises 29 countries for a period of 14 years, with 406 observations. ${ }^{10}$

The data consists of one agricultural aggregate output variable, defined as production net of amounts of various commodities used as feed and seed. The output series is based on 1999-2001 international commodity average prices $^{11}$ (1999-2001 I\$) and is expressed in a single currency unit. The international commodity prices are used in order to avoid using exchange rates to obtain continental and world aggregates, and also to improve and facilitate international comparative analysis of productivity at nation level. These international prices, expressed in so-called international dollars, are derived by FAO for the agricultural sector, using the Geary-Khamis method. This method assigns a single price to each commodity. ${ }^{12}$ The commodities covered in the computation are all crops and livestock products that each country produces. Almost all products are covered, the main exception being fodder crops.

The data consists of five input variables: land, agricultural tractors, agricultural population, fertilizer and livestock. Land comprises land for arable land and permanent crops, as well as the area under permanent meadows and pastures. It is measured in 1,000 ha. Arable land is the land under temporary agricultural crops (multiple-cropped areas are counted only once), temporary meadows for mowing or pasture, land under market and kitchen gardens and land temporarily fallow ( $<5$ years). The abandoned land resulting from shifting cultivation is not included in this category. Permanent crops cover land cultivated with long-term crops which do not have to be replanted for several years, land under trees and ornamental flowering shrubs (such as roses and jasmine), and nurseries. Permanent meadows and pastures cover land used permanently (5 years or more) to grow herbaceous forage crops, whether cultivated or wild (wild prairies or grazing land). Agricultural tractors refers to wheeled and crawler or track-laying tractors (excluding garden tractors) used in agriculture, without reference to the horsepower of tractors. It is measured in number

\footnotetext{
${ }^{9}$ FAOSTAT is an on-line multilingual database currently containing over 1 million time-series records from over 210 countries and territories providing statistics on crops, livestock, irrigation, land use, fertilizer, pesticide consumption, and agricultural machinery. Pesticide consumption series are still sparsely available.

10 Belgium and Luxembourg are aggregated.

11 The output series depends on the base 1999-2001. Changing the base to another reference year may potentially influence the results.

12 For example, one metric ton of wheat has the same price regardless of which country it was produced in. The currency unit in which the prices are expressed has no influence on the indices published.
} 
Table 1 Descriptive statistics, 1993-2006

\begin{tabular}{llrrrr}
\hline Variables & Units & \multicolumn{1}{l}{ Avg } & \multicolumn{1}{l}{ Min } & \multicolumn{1}{l}{ Max } & \multicolumn{1}{c}{ Std } \\
\hline Agr. output & $\times 10^{3} \mathrm{I} \$$ & $8,281,701.2$ & $53,350.0$ & $38,125,640.0$ & $9,950,171.2$ \\
Land & $\times 10^{3} \mathrm{ha}$ & $8,335.2$ & 9.0 & $41,223.0$ & $10,174.4$ \\
Machinery & $\times 10^{3} \mathrm{tr}$ & 349.1 & 0.5 & $1,900.0$ & 458.2 \\
Labour & $\times 10^{3} \mathrm{pe}$ & 875.9 & 2.0 & $10,454.0$ & $1,854.0$ \\
Fertilizer & $\times 10^{3} \mathrm{mt}$ & 740.6 & 0.9 & $5,064.0$ & $1,019.5$ \\
Livestock & $\times 10^{3} \mathrm{su}$ & $42,007.8$ & 236.8 & $191,956.0$ & $50,067.3$ \\
\hline
\end{tabular}

$I \$$ international dollar price, $h a$ hectare, $t r$ number of tractors, pe number of persons, $m t$ metric tons, su sheep equivalent units

Source: FAOSTAT (2010)

(no.) of tractors in use. Agricultural population is defined as all persons depending for their livelihood on agriculture, hunting, fishing and forestry. It comprises all persons economically active in agriculture as well as their non-working dependants. This population is not necessarily exclusively rural. ${ }^{13}$ It is measured in thousands $(1,000)$. Fertilizer is an aggregate of Nitrogen $(\mathrm{N})$, Potassium $\left(\mathrm{P}_{2} \mathrm{O}_{2}\right)$ and Phosphate $\left(\mathrm{K}_{2} \mathrm{O}\right)$ consumed in agriculture and expressed in tonnes of nutrients. Livestock is constructed by aggregating five categories of animals into sheep equivalents. The categories of animals considered are buffalo, cattle, pigs, sheep and goats. Numbers of these animals are converted into sheep equivalents using the same conversion factors as in Coelli and Prasada Rao (2005). Table 1 presents descriptive statistics for the data.

\section{Results and discussion}

This section presents some basic agricultural and economic indicators and discusses the estimates obtained. Agriculture represents a larger share of the GDP in EU-12 and CC than in EU-15 (see Table 2). It accounts for a large share of total employment, especially in Greece, Portugal, Latvia, Poland, Romania and Turkey. The percentage of agricultural area utilized is highest in Finland and Sweden and lowest in the United Kingdom. Compared to other countries, Poland and Turkey have a relatively high labour-to-land ratio, and at the same time have a very high unemployment rate. Inflation is particularly important in Bulgaria, Estonia, Latvia, Lithuania, Romania and Turkey.

Average annual agricultural output growth rates are highest in Spain and lowest in Belgium-Luxembourg (see Table 3). Within the EU-12 countries, the Baltic states, together with Slovakia, experienced the largest contractions in production, mainly due to the negative effect of the transition reform on capital-intensive agricultural production (i.e. the livestock sector), which is an important sector in these countries. ${ }^{14}$ The adjustment in input use varies greatly between countries.

\footnotetext{
13 It is likely that this variable overestimates the labour input used in agriculture.

14 In Estonia, animal production represented $58.6 \%$ of the average value of agricultural production between 1998 and 1999.
} 
Table 2 Selected economic indicators in agriculture, 1994-2006

\begin{tabular}{|c|c|c|c|c|c|c|}
\hline & $\begin{array}{l}\text { Share of } \\
\text { agriculture } \\
\text { in GDP } \\
(\%)\end{array}$ & $\begin{array}{l}\text { Share of } \\
\text { agriculture in } \\
\text { total } \\
\text { employment } \\
(\%)\end{array}$ & $\begin{array}{l}\text { Utilized } \\
\text { agricultural } \\
\text { area (\% of } \\
\text { total area) }\end{array}$ & $\begin{array}{l}\text { Labour: } \\
\text { land } \\
\text { ratio } \\
\text { (pers./ } \\
\text { ha) }\end{array}$ & $\begin{array}{l}\text { Unemployment } \\
(\%)\end{array}$ & $\begin{array}{l}\text { Inflation } \\
\text { rate (GDP } \\
\text { deflator) } \\
(\%)\end{array}$ \\
\hline \multicolumn{7}{|l|}{ EU-15 } \\
\hline Austria & 1.8 & 4.9 & 39 & 0.06 & 5 & 2 \\
\hline Bel.-Lux. & 1.1 & 1.4 & 45 & 0.06 & $8-5$ & $2-6$ \\
\hline Denmark & 2.2 & 3.6 & 63 & 0.04 & 4 & 2 \\
\hline Finland & 3.0 & 5.2 & 8 & 0.06 & 8 & 1 \\
\hline France & 2.4 & 3.2 & 54 & 0.03 & 9 & 2 \\
\hline Germany & 1.1 & 2.4 & 49 & 0.06 & 10 & 1 \\
\hline Greece & 5.2 & 16.1 & 64 & 0.09 & 9 & 3 \\
\hline Ireland & $2.8^{*}$ & 9.1 & 62 & 0.04 & 4 & 2 \\
\hline Italy & 2.4 & 5.0 & 47 & 0.09 & 7 & 2 \\
\hline Netherlands & 2.4 & 3.2 & 57 & 0.14 & 4 & 2 \\
\hline Portugal & 3.5 & 12.3 & 38 & 0.18 & 8 & 3 \\
\hline Spain & 3.4 & 6.9 & 57 & 0.05 & 9 & 4 \\
\hline Sweden & 1.8 & 3.0 & 8 & 0.05 & 7 & 2 \\
\hline UK & 0.9 & 1.7 & 73 & 0.03 & 5 & 3 \\
\hline \multicolumn{7}{|l|}{ EU-12 } \\
\hline Bulgaria & 5.6 & 4.5 & 47 & 0.05 & 9 & 8 \\
\hline Czech Rep. & 2.3 & 6.8 & 55 & 0.10 & 7 & 1 \\
\hline Cyprus & NA & 6.1 & 17 & 0.22 & 5 & 3 \\
\hline Estonia & 2.9 & 9.6 & 19 & 0.08 & 6 & 7 \\
\hline Hungary & 4.0 & 8.3 & 65 & 0.08 & 7 & 4 \\
\hline Latvia & 2.8 & 10.0 & 30 & 0.08 & 7 & 10 \\
\hline Lithuania & 3.7 & 9.0 & 43 & 0.07 & 6 & 7 \\
\hline Malta & NA & 1.2 & 29 & 0.24 & 7 & 3 \\
\hline Poland & 4.5 & 18.3 & 53 & 0.22 & 14 & 2 \\
\hline Romania & 12.8 & 10.7 & 59 & 0.12 & 7 & 11 \\
\hline Slovakia & 2.6 & 7.6 & 40 & 0.11 & 13 & 3 \\
\hline Slovenia & 1.8 & 0.9 & 25 & 0.04 & 6 & 2 \\
\hline \multicolumn{7}{|l|}{$\mathrm{CC}$} \\
\hline Croatia & 6.7 & 5.3 & 22 & 0.10 & 11 & 3 \\
\hline FYROM & 9.8 & 8.8 & 42 & 0.09 & 36 & 4 \\
\hline Turkey & 9.5 & 34.8 & 51 & 0.24 & 10 & 9 \\
\hline
\end{tabular}

* Series only available up to 2005. Data on inflation refer to the year 2006

Source: FAOSTAT (2010)

On average, labour, livestock and land inputs contracted over time, but the use of fertilizers and machinery increased. The largest labour contraction is found in Slovenia, though in an exception to the rule, livestock did not decline appreciably 
Table 3 Average annual output and input growths in agriculture, 1993-2006

\begin{tabular}{lrrrrrr}
\hline & Agr. output & Land & Machinery & Labour & Fertilizer & Livestock \\
\hline EU-15 & & & & & & \\
Austria & 0.3 & -0.4 & -0.2 & -2.9 & -2.4 & -1.5 \\
Bel.-Lux. & -3.2 & 0.1 & -0.7 & -2.7 & -0.6 & -0.9 \\
Denmark & 0.3 & -0.1 & -2.3 & -3.5 & -3.2 & -0.7 \\
Finland & 0.4 & -0.2 & -0.9 & -3.4 & 6.3 & -1.4 \\
France & 0.1 & -0.2 & -1.2 & -3.8 & -1.8 & -0.3 \\
Germany & 0.3 & -0.1 & -2.2 & -3.9 & -0.9 & -1.4 \\
Greece & -0.4 & -0.7 & 0.8 & -1.8 & -2.7 & 0.1 \\
Ireland & 0.1 & -0.2 & 0.1 & -0.5 & -2.0 & 0.6 \\
Italy & 0.0 & -0.8 & 1.9 & -4.0 & -2.2 & -1.0 \\
Netherlands & -0.7 & -0.2 & -1.2 & -1.7 & -2.7 & -1.7 \\
Portugal & 1.0 & -0.7 & 1.3 & -2.0 & -3.0 & 0.3 \\
Spain & 2.1 & -0.3 & 1.8 & -2.6 & 0.1 & 1.2 \\
Sweden & -0.6 & -0.4 & -0.2 & -2.5 & -2.1 & -1.0 \\
UK & -0.4 & 0.1 & 0.0 & -1.2 & -1.9 & -1.2 \\
EU-12 & & & & & & \\
Bulgaria & -0.8 & -1.2 & -0.9 & -6.5 & 1.6 & -4.3 \\
Czech Rep. & -1.4 & 0.0 & 0.4 & -2.6 & 2.1 & -4.0 \\
Cyprus & -0.6 & 0.0 & -2.1 & -2.6 & -2.6 & 1.3 \\
Estonia & -2.0 & -3.4 & -2.1 & -3.0 & -3.7 & -5.6 \\
Hungary & 1.2 & -0.4 & 2.2 & -3.3 & 4.6 & -2.7 \\
Latvia & -3.1 & -1.8 & 0.1 & -3.1 & 3.9 & -6.4 \\
Lithuania & -1.6 & -1.1 & 3.0 & -4.9 & 9.5 & -4.5 \\
Malta & 1.7 & -2.2 & 0.8 & -2.4 & 2.1 & -1.3 \\
Poland & -1.3 & -1.1 & 1.6 & -2.4 & 3.3 & -1.6 \\
Romania & 0.7 & -0.4 & 0.7 & -5.2 & -2.6 & -2.2 \\
Slovakia & -2.3 & -1.6 & -2.3 & -2.1 & 5.2 & -5.3 \\
Slovenia & 0.6 & -0.9 & 1.4 & -7.9 & 1.7 & -0.5 \\
CC & & & & & & \\
Croatia & 0.4 & -3.8 & 2.4 & -6.3 & 6.3 & -0.3 \\
FYROM & 1.9 & -0.3 & 0.9 & -4.1 & -3.1 & -2.1 \\
Turkey & 1.5 & 0.1 & 2.4 & -0.5 & 0.5 & -1.6 \\
\hline Source: FAOSTAT & $(2010)$ & & & & & \\
\hline & & & & & \\
\hline
\end{tabular}

Source: FAOSTAT (2010)

there. Livestock declined particularly in the Baltic States and Slovakia, in line with the earlier-mentioned finding on the decline of livestock products.

Although, fertilizer use declined in all EU-15 countries except Finland and Spain, it increased in the majority of the EU-12 countries, especially in Lithuania, where poor-quality soils prevail. Machinery stocks rose significantly in Lithuania and Hungary. With the exception of Estonia, Malta and Croatia, land input did not vary much over time (see also Lerman et al. 2003:1012; Macours and Swinnen 2000: 174). 
Poland and Slovakia had among the lowest annual rate of decline in labour within the EU-12 countries, which it may be attributed to the social buffer function of agriculture. In pre-transition industry, labour outflow was avoided by creating 'overfull employment' (Holzman 1955:455), facilitated by 'soft budget constraints' (Kornai 1986:3-30). However, hidden unemployment in agriculture had a different source, as farming represented the only way of obtaining a livelihood, especially in the case of small and privately owned farms. At the same time, farming's role as a safety net constrained the outflow of labour from agriculture in many EU-12 countries, inhibiting agricultural labour productivity and the modernization of the sector.

The estimates of the empirical model are now presented and discussed. First, the TFEs model is discussed and then compared to the standard model. For simplicity and ease of interpretation, all variables are rescaled before estimation, in order to have unit means. This allows the estimated first-order coefficients of a translog production frontier to be interpreted in terms of production elasticities (when evaluated at the sample average). One of the main advantages of the Bayesian approach is that during estimation, regularity conditions can be imposed through inequality restrictions, to ensure that input elasticities are nonnegative (i.e. monotonicity in input elasticities) at all observed input levels and thus that the production frontier is well-behaved. ${ }^{15}$ This is done following Terrell (1996). The enforcement of regularity conditions also helps to mitigate potential multicollinearity problems during the estimation.

The Gibbs sampler was run for one chain, with burn-in of 5,000 iterations, 195,000 retained draws and a thinning to every 15 th draw in order to decrease the autocorrelation of the chain. The accuracy of the estimation is checked by comparing the Monte Carlo (MC) error, which measures the variability of each estimate due to the simulation, with the corresponding posterior standard deviation. When the MC errors are lower than the standard deviation, convergence is normally achieved (Ntzoufras 2009:120).

At the sample average, the estimates of the production elasticities (see Table 4) are 0.34 for land, 0.05 for machinery, 0.08 for labour, 0.08 for fertilizer, and 0.47 for livestock. Unlike classical econometric approaches, the Bayesian approach allows the posterior kernel density to be recovered for all parameter estimates instead of for a single point estimate. This allows more information to be obtained on the underlying parameter uncertainty (see Fig. 1).

The parameter $\beta 1$ has a larger uncertainty than the other first order parameter estimates that have a wider kernel density. The first-order coefficients for land and livestock are relatively far from zero, indicating a notable contribution in explaining the response variable. All first-order coefficients have an unambiguous positive association with the response variable when the sign of the posterior summaries of central and relative location is considered; this implies that the production frontier is

\footnotetext{
15 Estimated translog functions often violate regularity conditions, including monotonicity. In most previous empirical applications, the required theoretical regularity conditions were not checked or tested, and conclusions were often drawn without critically assessing theoretical consistency. Computation of technical efficiency and measurement of productivity when units operate in the 'third stage' of a technology are inconsistent, because the third stage represents an economically inefficient region.
} 
Table 4 Bayesian estimated parameters of the stochastic production frontier

\begin{tabular}{|c|c|c|c|c|c|c|}
\hline Parameter & Avg & Std & MC err. & $2.5 \%$ & Median & $97.5 \%$ \\
\hline$\beta 1$ & 0.3363 & 0.0623 & 0.0024 & 0.2191 & 0.3363 & 0.4609 \\
\hline$\beta 2$ & 0.0476 & 0.0166 & 0.0006 & 0.0204 & 0.0457 & 0.0848 \\
\hline$\beta 3$ & 0.0775 & 0.0224 & 0.0006 & 0.0397 & 0.0755 & 0.1274 \\
\hline$\beta 4$ & 0.0772 & 0.0180 & 0.0005 & 0.0445 & 0.0763 & 0.1149 \\
\hline$\beta 5$ & 0.4593 & 0.0440 & 0.0016 & 0.3733 & 0.4592 & 0.5453 \\
\hline$\beta \mathrm{t}$ & 0.0077 & 0.0040 & 0.0001 & -0.0004 & 0.0078 & 0.0151 \\
\hline$\beta 11$ & 0.0777 & 0.0538 & 0.0024 & -0.0216 & 0.0753 & 0.1813 \\
\hline$\beta 12$ & -0.0190 & 0.0154 & 0.0006 & -0.0499 & -0.0184 & 0.0088 \\
\hline$\beta 13$ & -0.0024 & 0.0272 & 0.0012 & -0.0606 & -0.0001 & 0.0483 \\
\hline$\beta 14$ & -0.0132 & 0.0199 & 0.0008 & -0.0545 & -0.0123 & 0.0235 \\
\hline$\beta 15$ & 0.0031 & 0.0616 & 0.0029 & -0.1144 & 0.0040 & 0.1148 \\
\hline$\beta 1 \mathrm{t}$ & 0.0021 & 0.0024 & 0.0001 & -0.0026 & 0.0022 & 0.0066 \\
\hline$\beta 22$ & -0.0009 & 0.0041 & 0.0001 & -0.0093 & -0.0008 & 0.0070 \\
\hline$\beta 23$ & 0.0022 & 0.0122 & 0.0004 & -0.0223 & 0.0022 & 0.0261 \\
\hline$\beta 24$ & -0.0150 & 0.0098 & 0.0003 & -0.0365 & -0.0143 & 0.0020 \\
\hline$\beta 25$ & 0.0394 & 0.0206 & 0.0008 & 0.0045 & 0.0378 & 0.0849 \\
\hline$\beta 2 \mathrm{t}$ & 0.0007 & 0.0010 & 0.0000 & -0.0014 & 0.0006 & 0.0028 \\
\hline$\beta 33$ & 0.0095 & 0.0229 & 0.0008 & -0.0359 & 0.0089 & 0.0561 \\
\hline$\beta 34$ & 0.0049 & 0.0133 & 0.0005 & -0.0230 & 0.0054 & 0.0295 \\
\hline$\beta 35$ & -0.0187 & 0.0281 & 0.0011 & -0.0723 & -0.0190 & 0.0378 \\
\hline$\beta 3 \mathrm{t}$ & 0.0017 & 0.0016 & 0.0000 & -0.0014 & 0.0017 & 0.0049 \\
\hline$\beta 44$ & 0.0191 & 0.0166 & 0.0006 & -0.0151 & 0.0199 & 0.0498 \\
\hline$\beta 45$ & 0.0070 & 0.0265 & 0.0011 & -0.0401 & 0.0054 & 0.0614 \\
\hline$\beta 4 \mathrm{t}$ & -0.0031 & 0.0020 & 0.0000 & -0.0070 & -0.0031 & 0.0009 \\
\hline$\beta 55$ & 0.0329 & 0.0783 & 0.0035 & -0.1118 & 0.0306 & 0.1887 \\
\hline$\beta 5 \mathrm{t}$ & -0.0007 & 0.0023 & 0.0001 & -0.0053 & -0.0008 & 0.0038 \\
\hline$\beta \mathrm{tt}$ & -0.0021 & 0.0005 & 0.0000 & -0.0030 & -0.0021 & -0.0012 \\
\hline$\lambda$ & 8.255 & 2.263 & 0.0341 & 4.465 & 8.040 & 13.280 \\
\hline$\sigma-2$ & 247.6 & 19.25 & 0.2231 & 211.2 & 247.1 & 286.6 \\
\hline
\end{tabular}

Subscripts on $\beta_{n}$ coefficients indicate inputs: $1=$ land, $2=$ machinery, $3=$ labour, $4=$ fertilizer, $5=$ livestock, $6=$ trend

Source: own estimates

well behaved and increasing in inputs. The sum of these input elasticities is slightly below 1.00, indicating that the technology exhibits moderate declining return to scale at the sample mean. The hypothesis of constant return to scale in the agricultural literature is often accepted, as noted in Cuesta (2000:148).

The first-order coefficient of the time trend variable provides information on the average annual rate of neutral technological change. The annual percentage change in output due to technological change is estimated to be $0.77 \%$. In order to depict 

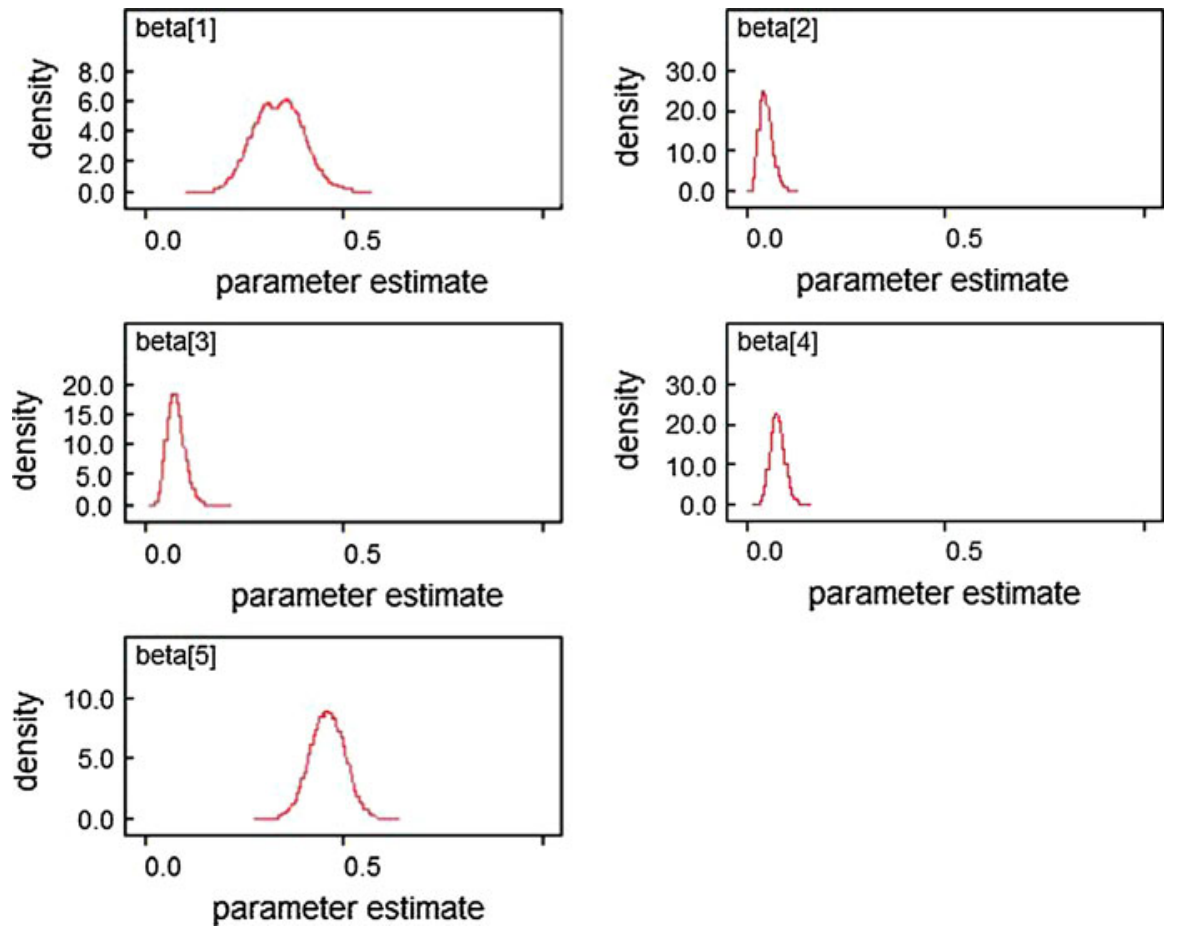

Fig. 1 Kernel densities of the first order parameter estimates (input elasticities)

non-monotonic technological change, a time-squared variable is introduced in the model, and a time interacted with each input variable (the latter to allow for nonneutral technological change). The coefficient of time squared is negative, indicating that the increase in the rate of technological change is slowing down through time. The coefficient of time interacted with the land, machinery, labour, fertilizer and livestock input variables is positive for land, machinery and labour, and negative for fertilizer and livestock. This suggests that during the period considered, technological change has been land-, machinery- and labour-saving, but fertilizer- and livestock-using. The country-specific intercepts for the TFEs model and the standard model are reported in the Appendix.

The parameters capturing the temporal variation of technical inefficiency are presented in Table 5. The estimated parameters of the temporal variation by country show that technical efficiency declined over time in 18 countries but increased in the remaining 11 countries. Negative trends in the temporal variation of technical inefficiency are predominant in EU-12 and CC.

Average technical efficiency scores by country are reported in Table 6 . Technical efficiency scores range from 0.2441 for Ireland to a maximum of 0.9074 for the Netherlands, with an unweighted country average of 0.4376 . The average technical efficiency scores imply that on average the countries were producing about $43.8 \%$ of the outputs that could be produced using the observed input quantities. The unweighted average technical efficiency score was 0.4984 for the EU-15 countries, 
Table 5 Bayesian estimated parameters of the temporal variation

\begin{tabular}{|c|c|c|c|c|c|c|}
\hline Parameter & Avg & Std & MC err. & $2.5 \%$ & Median & $97.5 \%$ \\
\hline$\eta 1$ & -0.0045 & 0.0034 & 0.0001 & -0.0107 & -0.0047 & 0.0026 \\
\hline$\eta 2$ & 0.0000 & 0.4991 & 0.0011 & -0.9800 & 0.0006 & 0.9793 \\
\hline$\eta 3$ & 0.0006 & 0.5007 & 0.0012 & -0.9796 & -0.0002 & 0.9810 \\
\hline$\eta 4$ & -0.0012 & 0.5002 & 0.0011 & -0.9785 & -0.0020 & 0.9789 \\
\hline$\eta 5$ & 0.0018 & 0.4986 & 0.0011 & -0.9751 & 0.0016 & 0.9826 \\
\hline$\eta 6$ & 0.0001 & 0.4995 & 0.0011 & -0.9810 & 0.0000 & 0.9811 \\
\hline$\eta 7$ & -0.0023 & 0.5000 & 0.0012 & -0.9844 & -0.0017 & 0.9761 \\
\hline$\eta 8$ & -0.0016 & 0.5008 & 0.0012 & -0.9852 & -0.0023 & 0.9790 \\
\hline$\eta 9$ & -0.0005 & 0.5006 & 0.0011 & -0.9798 & 0.0002 & 0.9820 \\
\hline$\eta 10$ & -0.0011 & 0.4988 & 0.0011 & -0.9740 & -0.0018 & 0.9786 \\
\hline$\eta 11$ & 0.0016 & 0.4990 & 0.0012 & -0.9760 & 0.0012 & 0.9827 \\
\hline$\eta 12$ & -0.0004 & 0.5009 & 0.0011 & -0.9807 & -0.0011 & 0.9790 \\
\hline$\eta 13$ & 0.0011 & 0.5017 & 0.0011 & -0.9837 & 0.0024 & 0.9838 \\
\hline$\eta 14$ & -0.0010 & 0.5000 & 0.0012 & -0.9782 & -0.0014 & 0.9807 \\
\hline$\eta 15$ & -0.0002 & 0.5000 & 0.0012 & -0.9792 & 0.0008 & 0.9776 \\
\hline$\eta 16$ & -0.0007 & 0.5002 & 0.0011 & -0.9780 & -0.0004 & 0.9771 \\
\hline$\eta 17$ & -0.0002 & 0.5003 & 0.0011 & -0.9821 & 0.0002 & 0.9795 \\
\hline$\eta 18$ & -0.0009 & 0.4999 & 0.0011 & -0.9764 & -0.0020 & 0.9782 \\
\hline$\eta 19$ & -0.0006 & 0.4997 & 0.0011 & -0.9847 & 0.0006 & 0.9820 \\
\hline$\eta 20$ & -0.0016 & 0.5007 & 0.0011 & -0.9843 & -0.0019 & 0.9797 \\
\hline$\eta 21$ & 0.0001 & 0.5006 & 0.0011 & -0.9823 & 0.0010 & 0.9776 \\
\hline$\eta 22$ & 0.0015 & 0.4998 & 0.0012 & -0.9764 & 0.0005 & 0.9821 \\
\hline$\eta 23$ & -0.0005 & 0.4999 & 0.0011 & -0.9830 & 0.0001 & 0.9780 \\
\hline$\eta 24$ & 0.0016 & 0.4996 & 0.0012 & -0.9745 & 0.0017 & 0.9791 \\
\hline$\eta 25$ & 0.0004 & 0.5000 & 0.0011 & -0.9780 & 0.0009 & 0.9774 \\
\hline$\eta 26$ & -0.0018 & 0.5003 & 0.0012 & -0.9826 & -0.0020 & 0.9823 \\
\hline$\eta 27$ & -0.0006 & 0.5010 & 0.0012 & -0.9836 & -0.0010 & 0.9798 \\
\hline$\eta 28$ & -0.0005 & 0.4988 & 0.0011 & -0.9799 & -0.0005 & 0.9734 \\
\hline$\eta 29$ & 0.0011 & 0.4993 & 0.0011 & -0.9824 & 0.0009 & 0.9787 \\
\hline
\end{tabular}

Subscript $i$ indicates inputs: $1=$ Austria, $2=$ Bel.-Lux., $3=$ Denmark, $4=$ Finland, $5=$ France, $6=$ Germany, $7=$ Greece, $8=$ Ireland, $9=$ Italy, $10=$ Netherlands, $11=$ Portugal, $12=$ Spain, $13=$ Sweden, $14=\mathrm{UK}, 15=$ Bulgaria, $16=$ Czech Rep., $17=$ Cyprus, $18=$ Estonia, $19=$ Hungary, 20 = Latvia;, 21 = Lithuania, 22 = Malta, 23 = Poland, 24 = Romania, 25 = Slovakia, 26 = Slovenia, $27=$ Croatia, $28=$ FYROM, $29=$ Turkey

Source: own estimates

0.3990 for the EU-12 countries and 0.3084, for the CC. Swinnen and Vranken (2005) argue that technical efficiency scores in market economies are typically close to the best-practice frontier. The results obtained for the EU-12 indicate that the inevitable collapse in agricultural output after market liberalization was not immediately followed by efficient reallocations of agricultural assets. Brada and King (1993:47-54) and Carter and Zhang (1994:326) note that massive privatization of the farm sector does not necessarily imply greater technical efficiency. The 
Table 6 Average technical efficiency scores by country, 1993-2006

\begin{tabular}{|c|c|c|c|c|c|c|}
\hline & Avg & Std & MC err. & $2.5 \%$ & Median & $97.5 \%$ \\
\hline \multicolumn{7}{|l|}{ EU-15 } \\
\hline Netherlands & 0.9074 & 0.0842 & 0.0022 & 0.6854 & 0.9323 & 0.9975 \\
\hline Belg.-Lux. & 0.6848 & 0.0718 & 0.0021 & 0.5123 & 0.6969 & 0.7959 \\
\hline Denmark & 0.6664 & 0.0910 & 0.0034 & 0.4691 & 0.6716 & 0.8286 \\
\hline Italy & 0.6585 & 0.1219 & 0.0044 & 0.4288 & 0.6550 & 0.9066 \\
\hline Greece & 0.5454 & 0.1004 & 0.0038 & 0.3511 & 0.5433 & 0.7423 \\
\hline Germany & 0.4758 & 0.0785 & 0.0025 & 0.3250 & 0.4741 & 0.6354 \\
\hline Austria & 0.4533 & 0.0703 & 0.0027 & 0.3093 & 0.4548 & 0.5854 \\
\hline Sweden & 0.4250 & 0.0690 & 0.0027 & 0.2852 & 0.4256 & 0.5558 \\
\hline Portugal & 0.4101 & 0.0668 & 0.0025 & 0.2732 & 0.4107 & 0.5365 \\
\hline Spain & 0.4068 & 0.0885 & 0.0032 & 0.2482 & 0.4016 & 0.5914 \\
\hline France & 0.4022 & 0.0807 & 0.0026 & 0.2578 & 0.3970 & 0.5736 \\
\hline Finland & 0.3917 & 0.0642 & 0.0024 & 0.2618 & 0.3922 & 0.5144 \\
\hline UK & 0.3055 & 0.0509 & 0.0016 & 0.2075 & 0.3049 & 0.4062 \\
\hline Ireland & 0.2441 & 0.0283 & 0.0009 & 0.1797 & 0.2473 & 0.2912 \\
\hline \multicolumn{7}{|l|}{ EU-12 } \\
\hline Hungary & 0.6518 & 0.1166 & 0.0044 & 0.4249 & 0.6497 & 0.8788 \\
\hline Czech Rep. & 0.4805 & 0.0803 & 0.0031 & 0.3181 & 0.4808 & 0.6329 \\
\hline Bulgaria & 0.4478 & 0.0802 & 0.0030 & 0.2930 & 0.4459 & 0.6052 \\
\hline Cyprus & 0.4381 & 0.0852 & 0.0029 & 0.2778 & 0.4346 & 0.6144 \\
\hline Slovakia & 0.4110 & 0.0692 & 0.0026 & 0.2720 & 0.4109 & 0.5441 \\
\hline Poland & 0.4033 & 0.0779 & 0.0028 & 0.2555 & 0.4008 & 0.5611 \\
\hline Slovenia & 0.3865 & 0.0662 & 0.0023 & 0.2568 & 0.3860 & 0.5180 \\
\hline Romania & 0.3735 & 0.0734 & 0.0027 & 0.2350 & 0.3712 & 0.5197 \\
\hline Malta & 0.3387 & 0.1157 & 0.0034 & 0.1671 & 0.3201 & 0.6154 \\
\hline Lithuania & 0.3327 & 0.0562 & 0.0021 & 0.2204 & 0.3325 & 0.4406 \\
\hline Latvia & 0.2688 & 0.0444 & 0.0016 & 0.1801 & 0.2687 & 0.3551 \\
\hline Estonia & 0.2557 & 0.0431 & 0.0015 & 0.1703 & 0.2553 & 0.3402 \\
\hline \multicolumn{7}{|l|}{$\mathrm{CC}$} \\
\hline Croatia & 0.3779 & 0.0623 & 0.0023 & 0.2524 & 0.3780 & 0.4979 \\
\hline Turkey & 0.2833 & 0.0661 & 0.0022 & 0.1664 & 0.2783 & 0.4232 \\
\hline FYROM & 0.2641 & 0.0443 & 0.0016 & 0.1759 & 0.2638 & 0.3505 \\
\hline
\end{tabular}

Source: own estimates

ranking within the EU-12 countries is very similar to the one previously obtained by Tonini and Jongeneel (2006), which highlights that the Central and Eastern European Countries that were the most advanced in their reforms (i.e. Hungary and Czech Republic) are also the countries performing best in terms of technical efficiency. Bulgaria's relatively good performance can be attributed to the large contraction in several key agricultural inputs (particularly labour and land), although, the agricultural output level remained fairly stable. A similar result was also reported by Lissitsa et al. (2007), who also explained that unlike other transition 

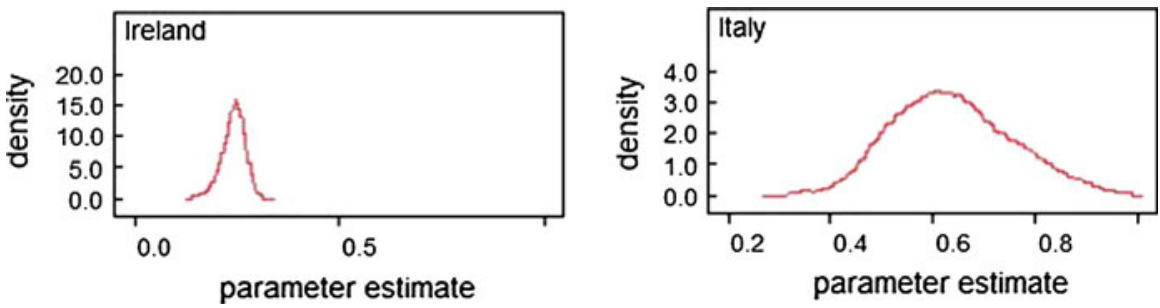

Fig. 2 Kernel densities of technical efficiency for Ireland and Italy

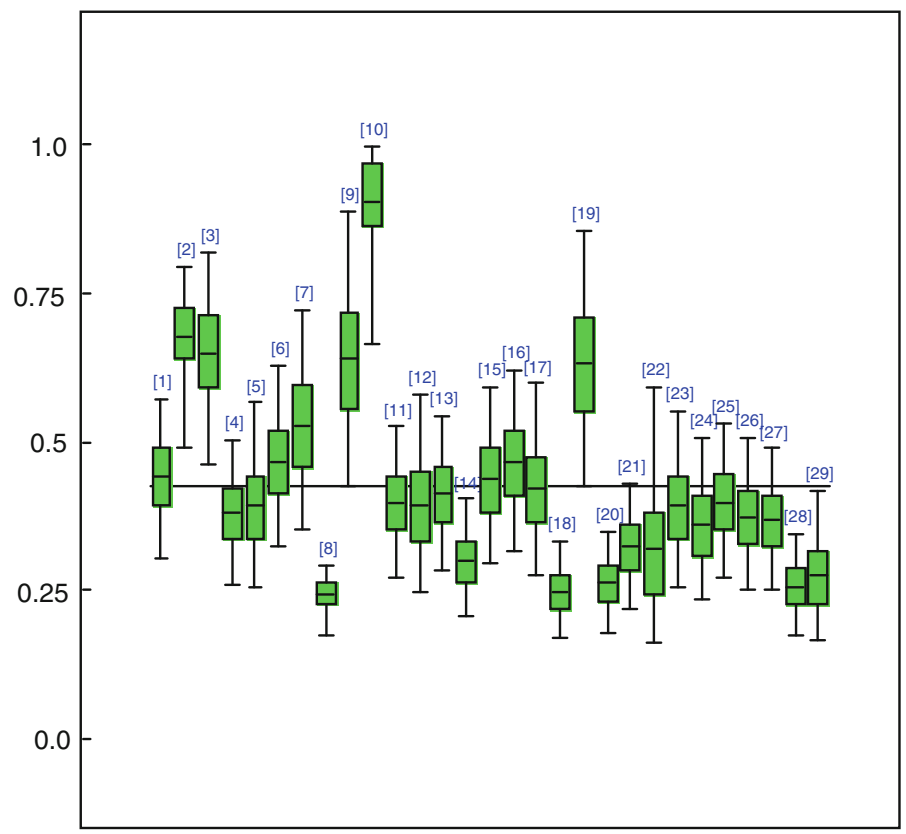

Fig. 3 Box plot of technological efficiencies by group of countries, 1993-2006. Numbers refer to countries: $1=$ Austria, $2=$ Bel.-Lux., $3=$ Denmark, $4=$ Finland, $5=$ France, $6=$ Germany, $7=$ Greece, $8=$ Ireland, $9=$ Italy, $10=$ Netherlands, $11=$ Portugal, $12=$ Spain, $13=$ Sweden, $14=$ UK, $15=$ Bulgaria, $16=$ Czech Rep., $17=$ Cyprus, $18=$ Estonia, $19=$ Hungary, $20=$ Latvia, $21=$ Lithuania,$\quad 22=$ Malta, $23=$ Poland,$\quad 24=$ Romania,$\quad 25=$ Slovakia,$\quad 26=$ Slovenia, $27=$ Croatia, $28=$ FYROM, $29=$ Turkey

countries the Bulgarian agricultural sector was highly subsidized by the government because of the relatively high contribution of agriculture to GDP.

Figure 2 provides the kernel densities for Ireland and Italy, two countries characterized by very different kernel densities. Compared to Italy, Ireland displays little variance around its mean. A box plot of efficiency scores is presented in Fig. 3. The horizontal line indicates the median technical efficiency for each country. The box contains the first and third quartiles that are the upper and lower boundaries of the middle $50 \%$ of the technical efficiency. The vertical lines, so-called whiskers, 
Table 7 Decomposition of TFP growth by country

\begin{tabular}{|c|c|c|c|c|}
\hline & Efficiency change & Technological change & Scale change & TFP change \\
\hline EU-15 & -0.0700 & 0.5404 & -0.0388 & 0.4416 \\
\hline Portugal & 0.1449 & 0.9575 & 0.0004 & 1.1027 \\
\hline Spain & -0.0405 & 0.8085 & 0.0805 & 0.8484 \\
\hline Greece & -0.2147 & 0.9277 & -0.0534 & 0.7261 \\
\hline Sweden & 0.1029 & 0.6116 & 0.0075 & 0.7219 \\
\hline Finland & -0.1094 & 0.6297 & 0.0468 & 0.5671 \\
\hline Italy & -0.0472 & 0.7890 & -0.1989 & 0.5429 \\
\hline France & 0.1632 & 0.5080 & -0.1434 & 0.5278 \\
\hline Denmark & 0.0584 & 0.3947 & -0.0180 & 0.4351 \\
\hline Austria & -0.4200 & 0.7673 & -0.0180 & 0.4351 \\
\hline Germany & 0.0051 & 0.5613 & -0.2414 & 0.3251 \\
\hline Bel.-Lux. & 0.0037 & 0.2696 & -0.0015 & 0.2718 \\
\hline UK & -0.0962 & 0.5112 & -0.1531 & 0.2619 \\
\hline Netherlands & -0.0993 & 0.3965 & -0.0518 & 0.2455 \\
\hline Ireland & -0.1519 & 0.3596 & 0.0029 & 0.2105 \\
\hline EU-12 & -0.0278 & 0.7974 & 0.0683 & 0.8378 \\
\hline Estonia & -0.0870 & 0.8936 & 0.8449 & 1.6516 \\
\hline Malta & 0.1431 & 0.3247 & 0.8887 & 1.3565 \\
\hline Latvia & -0.1503 & 0.9970 & 0.4846 & 1.3313 \\
\hline Romania & 0.1484 & 1.1828 & -0.2148 & 1.1164 \\
\hline Slovakia & 0.0368 & 0.8079 & 0.2360 & 1.0807 \\
\hline Lithuania & 0.0081 & 0.8545 & 0.1167 & 0.9793 \\
\hline Bulgaria & -0.0190 & 0.9082 & 0.0653 & 0.9544 \\
\hline Poland & -0.0457 & 0.9975 & -0.1888 & 0.7631 \\
\hline Hungary & -0.0511 & 0.7858 & -0.0016 & 0.7330 \\
\hline Czech Rep. & -0.0664 & 0.7372 & -0.0082 & 0.6626 \\
\hline Cyprus & -0.0217 & 0.5524 & 0.1112 & 0.6418 \\
\hline Slovenia & -0.1631 & 0.3929 & 0.1885 & 0.4183 \\
\hline $\mathrm{CC}$ & 0.0916 & 1.1633 & -0.1542 & 1.1001 \\
\hline Turkey & 0.0979 & 1.1940 & -0.1727 & 1.1192 \\
\hline FYROM & -0.0490 & 1.0004 & 0.1175 & 1.0689 \\
\hline Croatia & -0.0516 & 0.5250 & 0.1284 & 0.6018 \\
\hline
\end{tabular}

Average annual changes in \%, 1993-2006

Growth rates for EU-15, EU-12 and CC are computed as weighted averages, where the weights are represented by the shares in agricultural production value for the year 2006

Source: own estimates

display either the maximum value or the location of twice the standard deviation, whichever is the smaller. The figure shows that the standard deviation around the point estimates is relatively large for Greece, Italy, Hungary and Malta. 
Table 8 Deviance information criterion for the estimated models

\begin{tabular}{lll}
\hline & TFEs & ST \\
\hline DIC & $5,689.79$ & $5,690.07$ \\
\hline
\end{tabular}

Source: own estimates

The decomposition of TFP growth for each country is presented in Table 7. The estimated weighted average annual TFP growth is 0.44 for the EU-15, 0.84 for the EU-12 and $1.10 \%$ for the CC. This suggests that on average the EU-12 and CC have annual productivity growth rates that are about double that of the EU-15. This is also consistent with the results found by Lissitsa et al. (2007). Given the observed strong decline in agricultural output induced by transition in nearly all EU-12 countries (with Hungary, Malta, Romania and Slovenia as exceptions) and taking account of the known immobility of production factors in agriculture, it would not have been surprising to find a decline in TFP. In spite of this, however, we find that agricultural TFP rose at a higher rate in the EU-12 than in the EU-15 countries. This is in line with Brada (1989:443), who found that technical progress did not decline when the relation between outputs and inputs was adjusted for systematic changes in efficiency. TFP growth ranges from 0.21 for Ireland to 1.63 for Estonia, with an unweighted average of 0.75. All the countries analysed showed productivity growth. Efficiency change ranges from -0.42 for Austria to 0.16 for France, with an unweighted average of -0.03 and 18 countries showing negative efficiency changes. Technological change ranges from 0.27 for Belgium to 1.19 for Turkey, with an unweighted average of 0.71 and none of the countries show productivity regression. Scale change ranges from -0.24 for Germany to 0.89 for Malta, with an unweighted average of 0.06 and Portugal displaying very small changes in scale. The estimates suggest that productivity growth was mostly driven by technological change.

The results of the TFEs model are compared to the results of the standard model, which does not take account of country-specific time-invariant heterogeneity. The deviance information criterion (DIC) introduced by Spiegelhalter et al. (2002) was used to compare both models (Table 8). A low value for DIC indicates a better fit for the model.

From the DIC it appears that although, the TFEs model has a lower DIC than the standard model, the difference is less than the minimum value of below two and therefore both models can be considered to be equally good. However, we retain the results of the TFEs model, because they account for country-specific time-invariant heterogeneity. In Fig. 4, the cumulative changes are reported for both models. The main difference is in the cumulative TEC. The standard model shows a very moderate increase in TEC whereas the TFE displays negative TEC. For the other cumulative changes, both models present very similar trends. Carroll et al. (2011) reported similar findings.

\section{Conclusions}

This paper estimated and compared TFP growth in agriculture for the EU countries and CC over the period 1993-2006. The data used were drawn from the FAOSTAT 

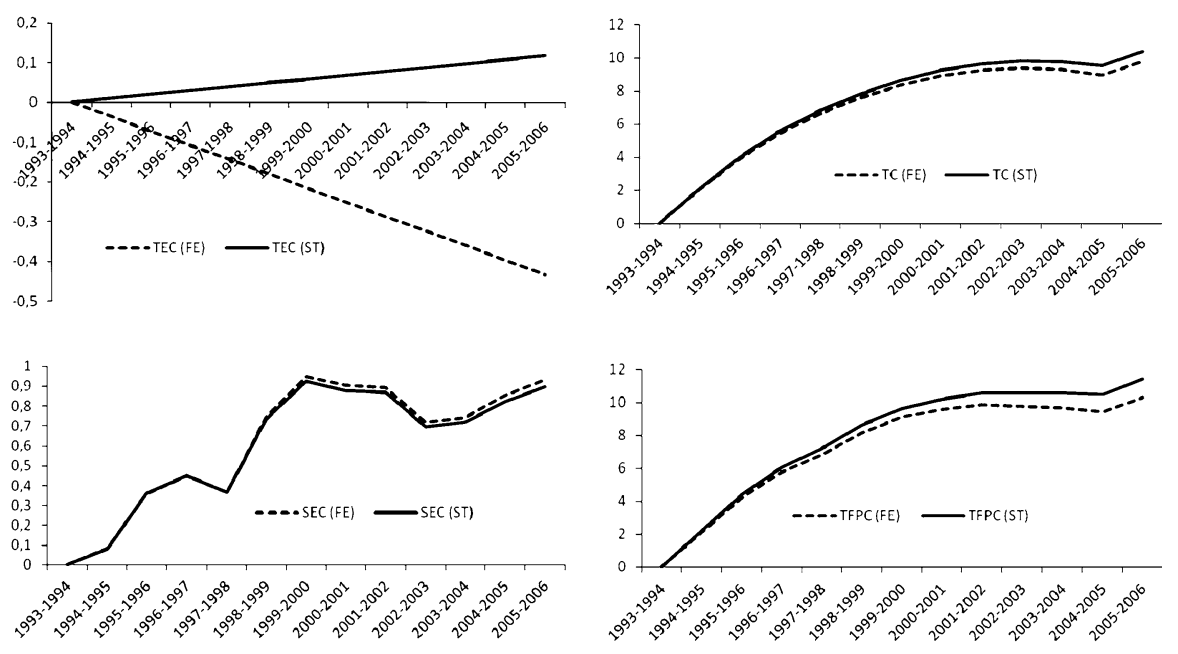

Fig. 4 Cumulative technical efficiency change (TEC), technological change (TC), scale efficiency change (SEC) and TFP change (TFPC) for the TFEs and ST models. Source own estimates

database of the Statistics Division of the FAO of the United Nations in Rome, which is the best available global database for cross-country comparisons in the agricultural sector. A Bayesian estimation framework was used, imposing global regularity conditions on the estimated production frontier and obtaining posterior kernel densities for each parameter estimate. Two types of nested models were estimated and compared: the extended TFEs model and the inefficiency model proposed by Cuesta (2000). Given the importance for country-level analysis of taking account of differences in the stage of development, market liberalization and physical conditions (soil quality, drainage, relief and climate), the TFEs model was preferred.

The main results illustrate important differences in the level and trends in agricultural productivity for European countries. On average, EU-15 countries used agricultural inputs more efficiently than the EU-12 countries and the CC. Agricultural productivity growth was mostly driven by advances in technology over time, through technological developments. Efficiency change contributed particularly to growth in agricultural productivity in EU-15 countries, whereas scale change contributed particularly to agricultural productivity in EU-12 countries and CC. Therefore, productivity gains were also due to moves toward the best practice frontier and to moves along the frontier. The EU-12 countries and CC displayed TFP growth rates that were about double the EU-15 growth rate. There was catch-up in productivity levels between EU-15 and EU-12 as well as between EU-15 and CC. Most of the countries that were well below the frontier at the beginning of the sample period had high TFP growth rates. This is especially the case for the Baltic States, Malta, Romania and Poland within the EU-12, and for Turkey and FYROM within the CC.

Care should be taken when interpreting the results, since they are conditional on the data and the assumptions underlying the estimation procedure used (for 
example: functional form, error-generating process, etc.). In addition, the data used do not allow differences in input quality to be controlled for. Input quality may differ across the countries considered in the analysis and so the results should be interpreted with this in mind. However, we believe that our results have drawn attention to several important trends in agricultural productivity.

Acknowledgments An earlier draft of this paper benefited from comments received in two separate seminar presentations given at the Department of Economics of Pablo Olavide University, Seville, Spain and at the Department of Economics of University of Oviedo, Oviedo, Spain. The author would also like to thank the two anonymous reviewers for helpful comments.

Open Access This article is distributed under the terms of the Creative Commons Attribution Noncommercial License which permits any noncommercial use, distribution, and reproduction in any medium, provided the original author(s) and source are credited.

\section{Appendix}

See Table 9.

Table 9 Intercepts of the ST and TFEs models

\begin{tabular}{|c|c|c|c|c|c|c|}
\hline Parameter & Avg & Std & MC err. & $2.5 \%$ & Median & $97.5 \%$ \\
\hline$\beta_{0}$ & 0.78 & 0.1794 & 0.01 & 0.4904 & 0.77 & 1.19100 \\
\hline$\alpha_{1}$ & 0.82 & 0.1787 & 0.01 & 0.5131 & 0.81 & 1.19400 \\
\hline$\alpha_{2}$ & -2.79 & 998.80 & 2.27 & $-1,955.00$ & -1.86 & $1,958.00$ \\
\hline$\alpha_{3}$ & -0.91 & $1,001.00$ & 2.22 & $-1,970.00$ & -2.68 & $1,961.00$ \\
\hline$\alpha_{4}$ & -1.94 & $1,001.00$ & 2.12 & $-1,962.00$ & -0.73 & $1,956.00$ \\
\hline$\alpha_{5}$ & 3.61 & $1,002.00$ & 2.38 & $-1,959.00$ & 2.08 & $1,967.00$ \\
\hline$\alpha_{6}$ & 1.22 & 999.80 & 2.16 & $-1,958.00$ & 2.61 & $1,951.00$ \\
\hline$\alpha_{7}$ & 1.34 & $1,003.00$ & 2.20 & $-1,963.00$ & 0.16 & $1,972.00$ \\
\hline$\alpha_{8}$ & 1.00 & $1,001.00$ & 2.30 & $-1,965.00$ & -0.37 & $1,962.00$ \\
\hline$\alpha_{9}$ & -3.78 & 999.40 & 2.19 & $-1,962.00$ & -3.43 & $1,958.00$ \\
\hline$\alpha_{10}$ & -0.35 & $1,004.00$ & 2.25 & $-1,961.00$ & -1.76 & $1,964.00$ \\
\hline$\alpha_{11}$ & 0.62 & $1,002.00$ & 2.20 & $-1,955.00$ & 1.54 & $1,954.00$ \\
\hline$\alpha_{12}$ & 0.46 & $1,002.00$ & 2.26 & $-1,968.00$ & 1.70 & $1,959.00$ \\
\hline$\alpha_{13}$ & -2.13 & 999.90 & 2.32 & $-1,967.00$ & -3.35 & $1,962.00$ \\
\hline$\alpha_{14}$ & -1.64 & 996.80 & 2.27 & $-1,964.00$ & -4.38 & $1,953.00$ \\
\hline$\alpha_{15}$ & -1.83 & $1,002.00$ & 2.51 & $-1,972.00$ & -3.02 & $1,955.00$ \\
\hline$\alpha_{16}$ & 1.38 & $1,002.00$ & 2.30 & $-1,966.00$ & 3.27 & $1,961.00$ \\
\hline$\alpha_{17}$ & 3.52 & $1,002.00$ & 2.28 & $-1,954.00$ & 3.02 & $1,967.00$ \\
\hline$\alpha_{18}$ & 2.99 & 998.80 & 2.28 & $-1,950.00$ & 1.54 & $1,956.00$ \\
\hline$\alpha_{19}$ & 3.69 & 999.30 & 2.27 & $-1,954.00$ & 3.66 & $1,966.00$ \\
\hline$\alpha_{20}$ & 2.95 & 998.90 & 2.33 & $-1,955.00$ & 5.10 & $1,964.00$ \\
\hline$\alpha_{21}$ & 1.60 & 999.40 & 2.15 & $-1,959.00$ & 2.12 & $1,965.00$ \\
\hline$\alpha_{22}$ & -0.63 & $1,001.00$ & 2.29 & $-1,966.00$ & 0.11 & $1,951.00$ \\
\hline$\alpha_{23}$ & -1.95 & $1,001.00$ & 2.21 & $-1,965.00$ & -1.90 & $1,961.00$ \\
\hline
\end{tabular}


Table 9 continued

\begin{tabular}{lrrlrrl}
\hline Parameter & \multicolumn{1}{l}{ Avg } & \multicolumn{1}{l}{ Std } & MC err. & \multicolumn{1}{l}{$2.5 \%$} & Median & $97.5 \%$ \\
\hline$\alpha_{24}$ & -0.02 & $1,001.00$ & 2.38 & $-1,962.00$ & -1.51 & $1,970.00$ \\
$\alpha_{25}$ & -2.38 & 996.60 & 2.31 & $-1,949.00$ & 0.42 & $1,943.00$ \\
$\alpha_{26}$ & -2.54 & $1,002.00$ & 2.21 & $-1,973.00$ & -0.31 & $1,950.00$ \\
$\alpha_{27}$ & 0.64 & 999.40 & 2.16 & $-1,959.00$ & 0.20 & $1,956.00$ \\
$\alpha_{28}$ & -0.83 & $1,003.00$ & 2.26 & $-1,972.00$ & -0.94 & $1,964.00$ \\
$\alpha_{29}$ & -0.75 & $1,002.00$ & 2.39 & $-1,968.00$ & 0.04 & $1,967.00$ \\
\hline
\end{tabular}

Source: own estimates

\section{References}

Aigner DJ, Lovell CAK, Schmidt PJ (1977) Formulation and estimation of stochastic frontier production function models. J Econom 6(1):21-37

Alvarez A, Corral J (2010) Identifying different technologies using a latent class model: extensive versus intensive dairy farms. Eur Rev Agric Econ 37(2):231-250

Battese GE, Coelli T (1992) Frontier production functions, technical efficiency and panel data: with application to paddy farmers in India. J Prod Anal 3(1-2):153-169

Battese GE, Corra G (1977) Estimation of a production frontier model with application to the pastoral zone of eastern Australia. Aust J Agric Econ 21(3):167-179

Brada JC (1989) Technological progress and factor utilization in Eastern European economic growth. Economica 56(224):433-448

Brada JC, King AE, Ma CY (1997) Industrial economics of the transition: determinants of enterprise efficiency in Czechoslovakia and Hungary. Oxf Econ Pap 49(1):104-127

Brada JC, King AE (1993) Is private farming more efficient than socialized agriculture? Economica 60(237):41-56

Carroll J, Newman C, Thorne F (2011) A comparison of stochastic frontier approaches for estimating technical inefficiency and total factor productivity. Appl Econ 43(27):4007-4019

Carter CA, Zhang B (1994) Agriculture efficiency gains in centrally planned economies? J Comp Econ 18(3):314-328

Caves DW, Christensen LR, Diewert WE (1982) The economic theory of index numbers and the measurement of input, output and productivity. Econometrica 50(6):1393-1414

Coelli TJ, Prasada Rao DS (2005) Total factor productivity growth in agriculture: a Malmquist index analysis of 93 countries. 1980-2000. Agric Econ 32(1):115-134

Coelli TJ, Prasada Rao DS, Battese GE (1998) An introduction to efficiency and productivity analysis. Kluwer, Boston

Cuesta R (2000) A production model with firm specific temporal variation in technical efficiency: with application to Spanish dairy farms. J Prod Anal 13(2):139-158

FAOSTAT (2010) FAOSTAT database. Food and Agriculture Organization of the United Nations. FAO, Rome

Fare R, Primont D (1995) Multi-output production and duality: theory and applications. Kluwer, Boston

Fulginiti LE, Perrin RK (1997) LDC agriculture: non parametric Malmquist productivity index. J Dev Econ 53(2):373-390

Greene WH (2004) Distinguishing between heterogeneity and inefficiency: stochastic frontier analysis of the World Health Organization's panel data on national health care systems. Health Econ 13:959-980

Greene WH (2005) Fixed and random effects in stochastic frontier models. J Prod Anal 23:7-32

Greene WH (2009) The econometric approach to efficiency analysis. In: Fried HO, Knox Lovell CA, Schmidt SS (eds) The measurement of productive efficiency and productivity growth. Oxford University Press, Oxford, pp 92-250

Griffin JE, Steel M (2004) Flexible mixture modelling of stochastic frontier. Technical report. University of Warwick, Warwick 
Griffin JE, Steel M (2007) Bayesian stochastic frontier analysis using WinBUGS. J Prod Anal 27(3):163-176

Holzman FD (1955) Unemployment in planned and capital economies. Q J Econ 69(3):452-460

Kennedy P (2003) A guide to econometrics. MIT Press, Cambridge

Koop G, Steel MFJ, Osiewalski J (1995) Posterior analysis of stochastic frontier models using Gibbs sampling. Comput Stat 10:353-373

Koop G, Osiewalski J, Steel MFJ (1999) The components of output growth: a stochastic frontier analysis. Oxf Bull Econ Stat 61(4):455-487

Kornai J (1986) The soft budget constraint. Kyklos 39(1):3-30

Kumbhakar SC (1990) Production frontiers and panel data time varying technical efficiency. J Econ 46(1-2):201-211

Kumbhakar SC, Hjalmarsson L (1993) Technical efficiency and technical progress in Swedish dairy farms. In: Fried HO, Knox Lovell CA, Schmidt SS (eds) The measurement of productive efficiency and productivity growth. Oxford University Press, Oxford, pp 257-270

Lerman Z, Kislev Y, Kriss A (2003) Agricultural output and productivity in the Former Soviet Republic. Econ Dev Cult Change 51(4):999-1018

Liefert W, Swinnen J (2002) Changes in agricultural markets in transition economies. Agricultural economic report no. 33945, United States Department of Agriculture, Economic Research Service, Washington DC

Lissitsa A, Rungsuriyawiboon S, Parkhomenko S (2007) How far are the transition countries from the economic standards of the European Union? East Eur Econ 45(3):51-75

Macours K, Swinnen J (2000) Causes of output decline in economic transition: the case of Central and Eastern European agriculture. J Comp Econ 28(1):172-206

Meeusen W, van den Broeck J (1977) Efficiency estimation from Cobb-Douglas production functions with composed error. Int Econ Rev 18(2):435-444

Murillo-Zamorano LR (2004) Economic efficiency and frontier techniques. J Econ Surv 18(1):33-77

Ntzoufras I (2009) Bayesian modeling using WinBUGS. Wiley, Hoboken

Orea L (2002) Parametric decomposition of a generalized Malmquist index. J Prod Anal 18(1):5-22

Schmidt P, Sickles RC (1984) Production frontier and panel data. J Bus Econ Stat 2(4):299-326

Spiegelhalter D, Best N, Carlin B, van der Linde A (2002) Bayesian measures of model complexity and fit (with discussion). J Roy Stat Soc 44:377-387

Spiegelhalter D, Thomas A, Best N, Lunn D (2003) WinBUGS user manual. Version 1.4, Jan 2003

Suhariyanto K, Thirtle C (2001) Asian agricultural productivity and convergence. J Agric Econ 52(3):96-110

Swinnen J, Vranken L (2005) Reforms and efficiency change in transition agriculture. In: Proceedings of the 11th congress of the European association of agricultural economists, August 24-27, Copenhagen

Terrell D (1996) Incorporating monotonicity and concavity conditions in flexible functional forms? J Appl Econ 11(2):179-194

Tonini A, Jongeneel R (2006) Is the collapse of agricultural output in the CEECs a good indicator of economic performance? East Eur Econ 44(4):32-59

Tsionas EG (2000) Full likelihood inference in normal-gamma stochastic frontier models. J Prod Anal 13(3):183-205

van den Broeck J, Koop G, Osiewalski J, Steel MFJ (1994) Stochastic frontier models: a Bayesian perspective. J Econ 61(2):273-303

Verbeek M (2004) A guide to modern econometrics, 2nd edn. Wiley, Chichester 